\title{
A De Novo Designed Metalloenzyme for the Hydration of $\mathrm{CO}_{2}{ }^{* *}$
}

\author{
Virginia M. Cangelosi, Aniruddha Deb, James E. Penner-Hahn, and Vincent L. Pecoraro*
}

\begin{abstract}
Protein design will ultimately allow for the creation of artificial enzymes with novel functions and unprecedented stability. To test our current mastery of nature's approach to catalysis, a $\mathrm{Zn}^{I I}$ metalloenzyme was prepared using de novo design. $\alpha_{3} \mathrm{DH}_{3}$ folds into a stable single-stranded three-helix bundle and binds $\mathrm{Zn}^{I I}$ with high affinity using $\mathrm{His}_{3} \mathrm{O}$ coordination. The resulting metalloenzyme catalyzes the hydration of $\mathrm{CO}_{2}$ better than any small molecule model of carbonic anhydrase and with an efficiency within 1400-fold of the fastest carbonic anhydrase isoform, CAII, and 11-fold of CAIII.
\end{abstract}

Protein design is an increasingly popular approach for studying and modeling the structure-function relationships in proteins. ${ }^{[1]}$ There is a growing interest in the development of artificial enzymes that can perform with the efficiency of natural enzymes toward reactions not normally seen in nature. Specifically, artificial metalloenzymes are important design targets because over one-third of natural proteins use metal ions for structural, catalytic, and/or electron-transfer functions. There are two main metalloprotein design strategies: protein redesign and de novo design. The former approach involves the introduction of a metal-binding site into an existing, stable protein. The latter relies on first principles to design well-defined structures from amino acid sequences not found in nature. De novo design is challenging owing to its requirement for complete control over folding and function, but it can lead to significant insight into the nature of metal-enzyme interactions. Several recent examples showcase the power of de novo design in creating metalloenzymes with enzymatic activity for ester hydrolysis, ${ }^{[2-5]}$ nitrite reduction, ${ }^{[6]}$ oxidation, ${ }^{[7,8]}$ and $N$-hydroxylation. ${ }^{[9]}$

One test of our current mastery of protein design is to model the activity of a natural enzyme. Carbonic anhydrase, which is ubiquitous in animals, plants, and bacteria, is essential for respiration, vision, regulation of acid-base equilibrium, and many other processes. One of the most

[*] Dr. V. M. Cangelosi, Dr. A. Deb, Prof. J. E. Penner-Hahn, Prof. V. L. Pecoraro

Department of Chemistry, University of Michigan

Ann Arbor MI, 48109 (USA)

E-mail: vlpec@umich.edu

[***] Research reported in this publication was supported by the National Institutes of Health under Award Numbers F32GM100543 (National Institute of General Medical Sciences) (V.M.C.) and R01ES012236 (National Institute of Environmental Health Sciences) (V.L.P.). The content is solely the responsibility of the authors and does not necessarily represent the official views of the National Institutes of Health.

Dig Supporting information for this article is available on the WWW under http://dx.doi.org/10.1002/anie.201404925. efficient enzymes in nature, human carbonic anhydrase II (CAII), catalyzes the reversible hydration of $\mathrm{CO}_{2}$ with a catalytic efficiency approaching the diffusion limit in water. The importance of this metalloenzyme, in conjunction with its well-studied mechanism, solid-state structure, and inhibition, make it a highly appealing, yet challenging, target to assess our ability to replicate the activity of a natural metalloenzyme in a simplified system.

Previously, we presented a highly efficient CA-mimic by modeling the active site within a de novo designed threestranded coiled-coil (3SCC). The bifunctional $\mathrm{Hg}^{\mathrm{II}}{ }_{\mathrm{S}} \mathrm{Zn}_{\mathrm{N}}^{\mathrm{II}}$ (TRIL9CL23H) ${ }_{3}$ closely models the structure of the $\mathrm{Zn}^{\mathrm{II}} \mathrm{His}_{3} \mathrm{OH}$ primary coordination sphere of CAII, yet places it within a very different fold ( $\alpha$-helices vs $\beta$-sheets in CAII), and contains an additional $\mathrm{Hg}^{\mathrm{II}} \mathrm{Cys}_{3}$ site which provides structural stability. The metalloenzyme catalyzes $\mathrm{CO}_{2}$ hydration with an efficiency comparable to some naturally occurring CAs and within 350-fold of the fastest isozyme, CAII. While this is the fastest CA-model to date, improvements to the system are limited by the inherent symmetry resulting from the self-assembly of three parallel $\alpha$ helices. Not only are antiparallel helices more typical in nature ${ }^{[10]}$ but CAII contains a network of $\mathrm{H}$-bonds that cannot currently be modeled in this system. Therefore, a new approach is required.

To allow for asymmetry in the secondary sphere of the active site, we have designed a metalloenzyme starting from $\alpha_{3} \mathrm{D}$, a de novo single-stranded antiparallel three-helix bundle. Designed by DeGrado and co-workers, ${ }^{[13]}$ this 73 amino acid protein folds with native protein-like stability, is tolerant of mutations within the hydrophobic core ${ }^{[14]}$ and has been structurally characterized by NMR spectroscopy. ${ }^{[12]}$ Previously, our lab incorporated a $\mathrm{Cys}_{3}$ metal binding site near the C-terminus of $\alpha_{3} \mathrm{D}$ and showed that the resulting protein, $\alpha_{3} \mathrm{DIV}$, binds $\mathrm{Hg}^{\mathrm{II}}, \mathrm{Pb}^{\mathrm{II}}$, and $\mathrm{Cd}^{\mathrm{II}}$ with high affinity in coordination geometries previously identified within the TRI family of 3SCCs. ${ }^{[15]}$ Herein, we report a new metalloenzyme, $\alpha_{3} \mathrm{DH}_{3}$, which contains a $\mathrm{His}_{3}$ site that, upon binding $\mathrm{Zn}^{\mathrm{II}}$, catalyzes the hydration of $\mathrm{CO}_{2}$ (Figure 1 ).

$\alpha_{3} \mathrm{DH}_{3}$ differs from $\alpha_{3} \mathrm{D}$ in that three leucine residues were replaced with histidine residues $(\mathrm{L} 18 \mathrm{H}, \mathrm{L} 28 \mathrm{H}, \mathrm{L} 67 \mathrm{H})$, a histidine residue was replaced with valine $(\mathrm{H} 72 \mathrm{~V})$ to ensure no competition for $\mathrm{Zn}^{\mathrm{II}}$ binding, and four extra residues were added to the end of the chain (GSGA) which improved expression yields (Table 1). Expressed from a synthetic gene in Escherichia coli, $\alpha_{3} \mathrm{DH}_{3}$ was purified by high-performance liquid chromatography (HPLC) and characterized by electrospray ionization mass spectroscopy (EI-MS). The observed molecular weight of $8283.5 \mathrm{Da}$ corresponds to the protein after deletion of the $\mathrm{N}$-terminal methionine residue $\left(\mathrm{MW}_{\text {calc }}=\right.$ 8283.1 Da). The protein is well-folded and stable according to circular dichroism spectroscopy (Supporting Information, 
a)

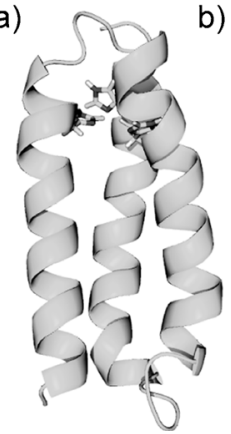

b)

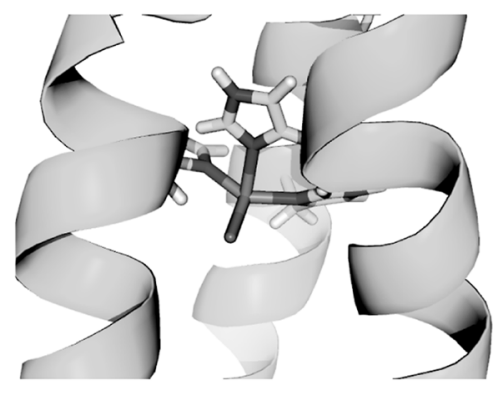

Figure 1. PyMol ${ }^{[1]}$ models of $\alpha_{3} \mathrm{DH}_{3}$ showing a) the entire bundle (last four residues removed for simplicity) and b) the $\mathrm{Zn}^{\prime \prime} \mathrm{His}_{3} \mathrm{O}$ site incorporating EXAFS Zn-N/O distances. Models are based on the NMR solution structure of $\alpha_{3} D$ (PDB: 2A3D). ${ }^{[12]}$

Table 1: Designed peptide sequences. ${ }^{[a]}$

\begin{tabular}{ll}
\hline Peptide & Sequence \\
\hline$\alpha_{3} \mathrm{DH}_{3}$ & MGSWAEFKQRLAAIKTRHQALGG \\
& SEAEHAAFEKEIAAFESELQAYKGKGNPE \\
& VEALRKEAAAIRDEHQAYR VNGSGA \\
$\alpha_{3} \mathrm{DH72V}$ & MGSWAEFKQRLAAIKTRLQALGG \\
& SEAELAAFEKEIAAFESELQAYKGKGNPE \\
& VEALRKEAAAIRDELQAYR $\boldsymbol{V N}$ \\
\hline
\end{tabular}

[a] Mutations with respect to $\alpha_{3} D$ are in bold and italics.

Figure S1). The observed double well at 208 and $222 \mathrm{~nm}$ is characteristic of $\alpha$-helical proteins, and the molar ellipticities suggest that the protein is $82 \%$ folded at $\mathrm{pH} 9$. Chemical denaturations with guanidine hydrochloride were fit to a twostate unfolding model, revealing a $\Delta G_{\mathrm{u}}=3.1 \mathrm{kcalmol}^{-1}$. Although the histidine substitutions destabilized the protein compared to native $\alpha_{3} \mathrm{D}\left(\Delta G_{\mathrm{u}}=5.1 \mathrm{kcal} \mathrm{mol}^{-1}\right)$, the construct is stable enough for use in kinetic studies. The presence of $\mathrm{Zn}^{\mathrm{II}}$ caused no change in the folding or stability of $\alpha_{3} \mathrm{DH}_{3}$ (Supporting Information, Figure S1).

Apparent $\mathrm{Zn}^{\mathrm{II}}$ binding constants were measured by UV/ Vis spectroscopy using Zincon as a colorimetric probe (Supporting Information, Figures S2-S4). $\alpha_{3} \mathrm{DH}_{3}$ binds $\mathrm{Zn}^{\mathrm{II}}$ with a $150 \pm 40 \mathrm{~nm}$ affinity at $\mathrm{pH} 7.5$, which strengthens to $59 \pm 9 \mathrm{~nm}$ at $\mathrm{pH}$ 9.0. A control peptide, $\alpha_{3} \mathrm{DH} 72 \mathrm{~V}$, which lacks the $\mathrm{His}_{3}$ binding site, binds with 20 -fold weaker affinity $\left(K_{\mathrm{d}}=\right.$ $1.2 \pm 0.4 \mu \mathrm{M}$ at $\mathrm{pH} 9.0$ ), confirming that the histidine site is involved in specific $\mathrm{Zn}^{\mathrm{II}}$ binding. These affinities are weaker than that of CAII measured by equilibrium dialysis $\left(K_{\mathrm{d}}=\right.$ $0.8 \pm 0.1 \mathrm{pm}) ;^{[16]}$ however, recent isothermal titration calorimetry experiments suggest a three-orders of magnitude weaker affinity for CAII $\left(K_{\mathrm{d}}=0.45 \mathrm{~nm}\right) \cdot{ }^{[17]}$ Based on this newer measurement, $\alpha_{3} \mathrm{DH}_{3}$ has an affinity only two orders of magnitude weaker than CAII and stronger than those observed for our previously published $\mathrm{Hg}^{\mathrm{II}}{ }_{\mathrm{S}} \mathrm{Zn}^{\mathrm{II}}{ }_{\mathrm{N}}$ (TRIL9CL23H $)_{3} \quad\left(K_{\mathrm{d}}=0.8 \pm 0.1 \quad\right.$ and $0.22 \pm$ $0.06 \mu \mathrm{M}$ at $\mathrm{pH} 7.5$ and 9.0, respectively). ${ }^{[18]}$

A sample of $\mathrm{Zn}^{\mathrm{II}} \alpha_{3} \mathrm{DH}_{3}$ at $\mathrm{pH} 9.0$ was analyzed by extended X-ray absorption fine structure (EXAFS) spectroscopy. The EXAFS data is dominated by nearest-neighbor scattering typical of oxygen or nitrogen ligation and can be

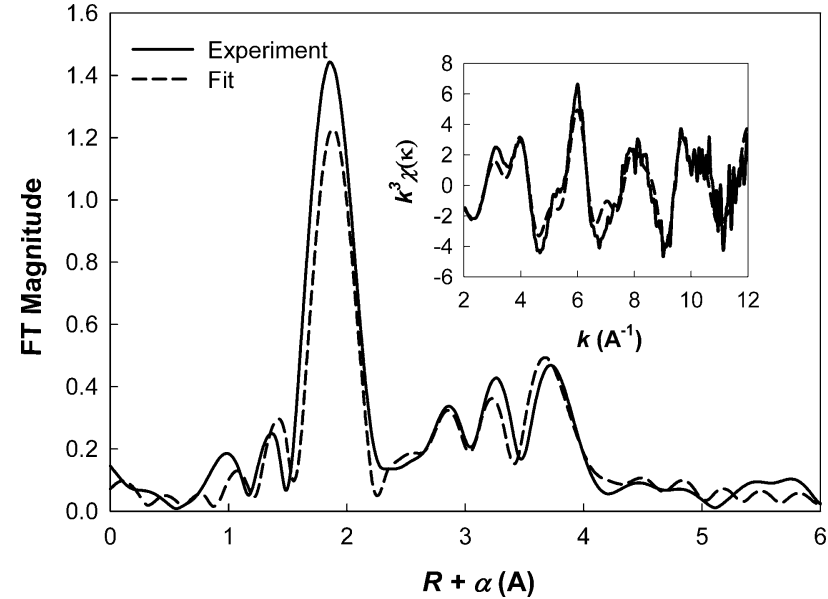

Figure 2. Fourier transform (FT) of the EXAFS spectra for $\mathrm{Zn}^{\prime \prime} \alpha_{3} \mathrm{DH}_{3}$. Inset is $k^{3}$-weighted EXAFS spectra used to calculate the FT. — Experimental data, ----- best-fit curve.

modeled with a single oxygen/nitrogen shell at about $1.98 \AA$, a distance consistent with a four-coordinate $\mathrm{Zn}$ site. There is clear evidence of outer shell scattering typical of histidine ligated metals (that is, features at $\mathrm{R}+\alpha>2 \AA$ in Figure 2). Given the relatively limited $k$ range of these data, there are multiple models with similar fit quality, making it difficult to define the number of histidine ligands from EXAFS alone. However, the best fit, both in terms of mean-square deviation and in terms of the presence of physically reasonable fit parameters, uses one oxygen at $1.90 \AA$ and 3 histidines at $1.99 \AA$. These parameters are very similar to EXAFS distances measured for CAII (Zn-N/O of $1.98 \AA){ }^{[17]}$

The true indication of a successfully designed metalloenzyme mimic is catalytic activity toward the physiological reaction of the natural enzyme, in this case, the hydration of $\mathrm{CO}_{2}$. Using Khalif's ${ }^{[19]}$ stopped-flow indicator technique, $\mathrm{Zn}^{\mathrm{II}} \alpha_{3} \mathrm{DH}_{3}$ was found to be an efficient catalyst with activities that increase with $\mathrm{pH}$ (Table 2). Testing the activity at a $\mathrm{pH}$ higher than 9.5 is not feasible because the stability of the bundle is compromised when interhelical salt bridges are deprotonated. Fitting the catalytic efficiencies for $\mathrm{pH}$ 8-9.5, a maximal efficiency of $6.9 \times 10^{4} \mathrm{~L} \mathrm{~mol}^{-1} \mathrm{~s}^{-1}$ and a kinetic $\mathrm{p} K_{\mathrm{a}}$ of 9.4 were derived (Figure 3). CAII has a $\mathrm{p} K_{\mathrm{a}}$ of $6.8^{20}$ for the deprotonation of $\mathrm{Zn}^{\mathrm{II}}$-bound water to give the active hydroxide complex. The $\mathrm{p} K_{\mathrm{a}}$ measured here might be for the same process (as was suggested for the observed $\mathrm{pK}_{\mathrm{a}}$ (8.8) for $p$-nitrophenylacetate hydrolysis by $\mathrm{Hg}_{\mathrm{S}}^{\mathrm{II}} \mathrm{Zn}_{\mathrm{N}}^{\mathrm{II}}$ (TRIL9CL23H) $)_{3}$ ); however, it could also be for a lysine residue near the active site, which, upon deprotonation, would open up the bundle and allow improved substrate access. In either case, catalysis occurs at the $\mathrm{Zn}^{\mathrm{II}} \mathrm{His}_{3} \mathrm{O}$ site; even in the presence of $\mathrm{Zn}^{\text {II }}$ the control peptide $\alpha_{3} \mathrm{DH} 72 \mathrm{~V}$ shows significantly lower activity (Supporting Information, Figure S5).

Numerous small molecule models for CAII have been reported, with varying degrees of structural similarity to the enzyme active site. ${ }^{[21-28]}$ Many of these show some catalytic activity toward the hydration of $\mathrm{CO}_{2}$, with the fastest catalysts listed in Table 2. Both $\mathrm{Zn}^{\mathrm{II}}$ (tris(4,5-di- $n$-propyl-2-imidazolyl)- 
Table 2: Kinetic parameters for the catalysis of $\mathrm{CO}_{2}$ hydration by enzymes and model complexes.

\begin{tabular}{|c|c|c|c|c|c|c|c|}
\hline Enzyme/Model & $\mathrm{p} K_{\mathrm{a}}$ & $\mathrm{pH}$ & $k_{\text {cat }}\left[\mathrm{s}^{-1}\right]$ & $K_{\mathrm{M}}[\mathrm{mm}]$ & $k_{\text {cat }} / K_{\mathrm{M}}\left[\mathrm{L} \mathrm{mol}^{-1} \mathrm{~s}^{-1}\right]$ & $k_{2}\left[\mathrm{~L} \mathrm{~mol}^{-1} \mathrm{~s}^{-1}\right]$ & Reference \\
\hline CAII & $6.8^{[a]}$ & 8.8 & $8.2 \times 10^{5}$ & 8.9 & $9.2 \times 10^{7}$ & & [29] \\
\hline CAIII & 8.5 & 9.0 & $8 \times 10^{3}$ & 20 & $4 \times 10^{5}$ & & [30] \\
\hline $\mathrm{Hg}^{\prime \prime} \mathrm{Zn}_{\mathrm{N}}\left({ }^{\prime \prime} \text { TRIL9CL23 H }\right)_{3}{ }^{\mathrm{n}+}$ & $8.82^{[b]}$ & 9.5 & $(1.8 \pm 0.4) \times 10^{3}$ & $10.0 \pm 2.4$ & $(1.8 \pm 0.3) \times 10^{5}$ & & [2] \\
\hline \multirow[t]{6}{*}{$\mathrm{Zn}^{\prime \prime} \alpha_{3} \mathrm{DH}_{3}$} & 9.4 & 9.5 & $134 \pm 8$ & $3.5 \pm 0.6$ & $(3.8 \pm 0.5) \times 10^{4}$ & & this work \\
\hline & & 9.25 & $137 \pm 8$ & $4.1 \pm 0.7$ & $(3.2 \pm 0.3) \times 10^{4}$ & & \\
\hline & & 9.0 & $103 \pm 8$ & $4.9 \pm 1.0$ & $(2.1 \pm 0.3) \times 10^{4}$ & & \\
\hline & & 8.75 & $107 \pm 12$ & $7.3 \pm 1.8$ & $\left(1.5 \pm(0.2) \times 10^{4}\right.$ & & \\
\hline & & 8.5 & $82 \pm 6$ & $7.2 \pm 1.1$ & $(1.1 \pm 0.1) \times 10^{4}$ & & \\
\hline & & 8.0 & $39 \pm 4$ & $6.2 \pm 1.7$ & $(0.63 \pm 0.1) \times 10^{4}$ & & \\
\hline Zn"([14]aneN4) & 9.8 & $\operatorname{ind}^{[c]}$ & & & & $5040^{[c]}$ & {$[35]$} \\
\hline $\mathrm{Zn}^{\prime \prime}([12] \mathrm{aneN} 4)$ & 8.1 & 9.1 & & & & $3012 \pm 193$ & {$[27]$} \\
\hline Zn"(nitrilotris (2-benzimidazolylmethyl-6-sulfonate) & 8.3 & 9.5 & & & & $3180^{[\mathrm{d}]}$ & [28] \\
\hline Zn"(tris (4,5-di-n-propyl-2-imidazolyl)phosphine) & 8.0 & 6.55 & & & & $2480^{[e]}$ & {$[25]$} \\
\hline
\end{tabular}

[a] Taken from Ref. [20]. [b] p $K_{\mathrm{a}}$ measured for the hydrolysis of $p N P A$. [c] pH-independent second-order rate constant (maximal rate) calculated using $\mathrm{p} K_{\mathrm{a}}$ of 9.8 and measured rate of $690 \mathrm{M}^{-1} \mathrm{~s}^{-1}$ at $\mathrm{pH}$ 9.0. [d] Second-order rate constant measured at $15^{\circ} \mathrm{C}$. [e] Second-order rate constant was measured for the dehydration of $\mathrm{HCO}_{3}{ }^{-}+\mathrm{H}^{+}$in $80 \% \mathrm{EtOH} / \mathrm{H}_{2} \mathrm{O}$.

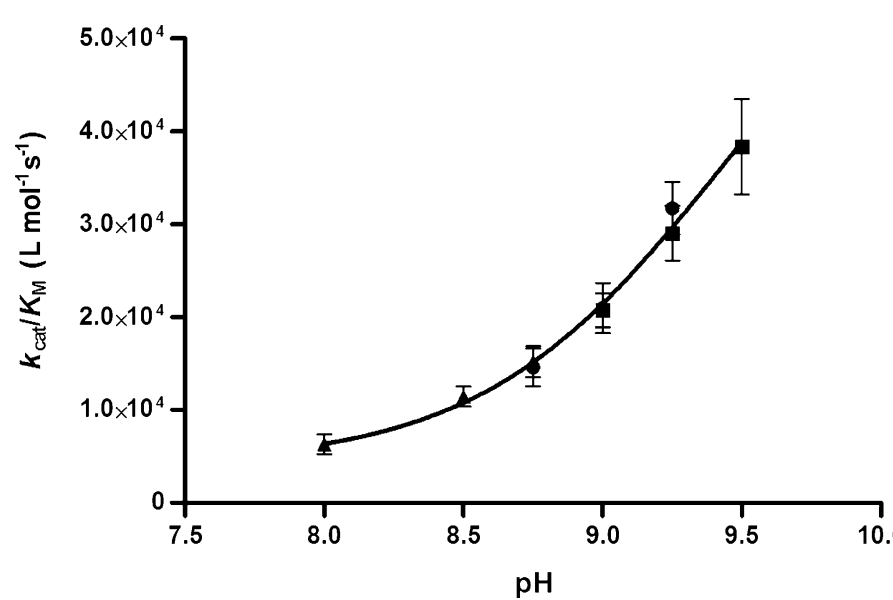

Figure 3. Plot of $\mathrm{pH}$ dependency of the catalytic efficiency of $\mathrm{CO}_{2}$ hydration by $\mathrm{Zn}^{\prime \prime}-\alpha_{3} \mathrm{DH}_{3}$. Standard errors for the fit of the MichaelisMenten equation to each plot of initial rate versus initial $\left[\mathrm{CO}_{2}\right]$. The buffer/indicator pairs used: $\Delta$ TAPS/ $m$-cresol purple $(\mathrm{pH} 8-8.75)$,

- AMPSO/thymol blue ( $\mathrm{pH} 8.75-9.25)$, a CHES/thymol blue $(\mathrm{pH}$ 9.25-9.5)

phosphine) and $\mathrm{Zn}^{\mathrm{II}}$ (nitrilotris(2-benzimidazolylmethyl-6sulfonate) have $\mathrm{N}_{3} \mathrm{O}$ coordination of the $\mathrm{Zn}^{\mathrm{II}}$ ion and show moderate activity. ${ }^{[25,28]} \mathrm{Zn}^{\mathrm{II}} \alpha_{3} \mathrm{DH}_{3}$ outperforms each of these with a maximal catalytic efficiency that is at least 14 -fold higher than their fastest second-order rate constants. Its efficiency is only 2.6-fold slower than that of

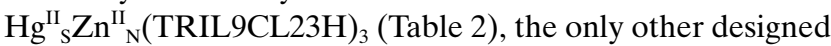
enzyme for $\mathrm{CO}_{2}$ hydration. ${ }^{[2]}$ Compared to the native enzymes, $\mathrm{Zn}^{\mathrm{II}} \mathrm{\alpha}_{3} \mathrm{DH}_{3}$ is 1400 -fold slower than CAII and only 11-fold slower than CAIII. ${ }^{[29,30]}$

A frequent problem with small-molecule models of enzymes is product inhibition. ${ }^{[31-33]}$ Using acetate as a more tractable mimic of the reaction product bicarbonate, product inhibition was tested (Supporting Information, Figure S5). Addition of $300 \mathrm{~mm}$ KOAc to the assay at $\mathrm{pH} 8.5$ resulted in a decrease in $k_{\text {cat }}$ from $82 \pm 6$ to $66 \pm 4 \mathrm{~s}^{-1}$. With an enzyme concentration of $100 \mu \mathrm{M}$ and $\mathrm{HCO}_{3}{ }^{-}$concentrations never exceeding $25 \mathrm{~mm}$, no significant loss in catalytic activity is expected owing to product inhibition. This shows that the peptide is well-designed to avoid product inhibition, highlighting one benefit of de novo design over small molecule catalysts.

In conclusion, we successfully modified an existing de novo designed protein to contain a $\mathrm{Zn}^{\mathrm{II}} \mathrm{His}_{3}$ binding site while retaining the desired fold. We report the first $\mathrm{pH}$ profile for $\mathrm{CO}_{2}$ hydration by a de novo designed protein and show that $\mathrm{Zn}^{\mathrm{II}} \alpha_{3} \mathrm{DH}_{3}$ catalyzes this reaction better than any small molecule model and within 1-3 orders of magnitude of natural CA isozymes. The efficiency of our single-stranded .0 construct is slightly lower than our previously reported 3SCC $\mathrm{Hg}^{\mathrm{II}}{ }_{\mathrm{S}} \mathrm{Zn}^{\mathrm{II}}{ }_{\mathrm{N}}$ (TRIL9CL23H $)_{3}$ and the $\mathrm{Zn}^{\mathrm{II}}$ affinity is stronger, likely a consequence of differences in the peptide scaffolds. The antiparallel bundle is expected to have a weaker dipole than the coiled-coil, imidazole rings in less-symmetric orientations, and different electrostatics around the binding site. Compared to $\mathrm{Hg}_{\mathrm{s}}^{\mathrm{II}} \mathrm{Zn}^{\mathrm{II}}{ }_{\mathrm{N}}$ (TRIL9CL23H) $)_{3}, \mathrm{Zn}^{\mathrm{II}} \alpha_{3} \mathrm{DH}_{3}$ has greater potential for improving catalysis because it is far easier to make asymmetric protein modifications in this system. Furthermore, being an antiparallel construct, $\mathrm{Zn}^{\mathrm{II}} \alpha_{3} \mathrm{DH}_{3}$ more faithfully reproduces helical structures found in nature. In CAII, mutation of Thr199 to alanine lowers the activity 100 -fold, showcasing the importance of second coordination sphere residues involved in hydrogen bonds. ${ }^{[34]}$ Future work will focus on site selective incorporation of acid-base catalytic residues or design of water channels that may tune the Lewis acidity of $\mathrm{Zn}^{\mathrm{II}}$ to optimize activity.

Received: May 2, 2014

Published online: June 18, 2014

Keywords: carbonic anhydrase - de novo design . metalloenzymes $\cdot$ protein design $\cdot$ zinc enzymes 
[1] F. Yu, V. M. Cangelosi, M. L. Zastrow, M. Tegoni, J. S. Plegaria, A. G. Tebo, C. S. Mocny, L. Ruckthong, H. Qayyum, V. L. Pecoraro, Chem. Rev. 2014, 114, 3495-3578.

[2] M. L. Zastrow, A. F. A. Peacock, J. A. Stuckey, V. L. Pecoraro, Nat. Chem. 2012, 4, 118-123.

[3] B. S. Der, D. R. Edwards, B. Kuhlman, Biochemistry 2012, 51 , $3933-3940$.

[4] S. D. Khare, Y. Kipnis, P. Greisen, R. Takeuchi, Y. Ashani, M. Goldsmith, Y. Song, J. L. Gallaher, I. Silman, H. Leader, J. L. Sussman, B. L. Stoddard, D. S. Tawfik, D. Baker, Nat. Chem. Biol. 2012, 8, 294-300.

[5] C. M. Rufo, Y. S. Moroz, O. V. Moroz, J. Stöhr, T. A. Smith, X $\mathrm{Hu}$, W. F. DeGrado, I. V. Korendovych, Nat. Chem. 2014, 6, $303-$ 309.

[6] M. Tegoni, F. Yu, M. Bersellini, J. E. Penner-Hahn, V. L. Pecoraro, Proc. Natl. Acad. Sci. USA 2012, 109, 21234-21239.

[7] M. Faiella, C. Andreozzi, R. T. M. de Rosales, V. Pavone, O. Maglio, F. Nastri, W. F. DeGrado, A. Lombardi, Nat. Chem. Biol. 2009, $5,882-884$.

[8] J. Kaplan, W. F. DeGrado, Proc. Natl. Acad. Sci. USA 2004, 101 $11566-11570$.

[9] A. J. Reig, M. M. Pires, R. A. Snyder, Y. Wu, H. Jo, D. W. Kulp S. E. Butch, J. R. Calhoun, T. Szyperski, E. I. Solomon, W. F. DeGrado, Nat. Chem. 2012, 4, 900-906.

[10] J. S. Richardson, Adv. Protein Chem. 1981, 34, 167-339.

[11] The PyMOL Molecular Graphics System, Version 1.5.0.4 Schrödinger, LLC.

[12] S. T. R. Walsh, H. Cheng, J. W. Bryson, H. Roder, W. F. DeGrado, Proc. Natl. Acad. Sci. USA 1999, 96, 5486-5491.

[13] J. W. Bryson, J. R. Desjarlais, T. M. Handel, W. F. DeGrado, Protein Sci. 1998, 7, 1404-1414.

[14] S. T. Walsh, V. I. Sukharev, S. F. Betz, N. L. Vekshin, W. F. DeGrado, J. Mol. Biol. 2001, 305, 361-373.

[15] S. Chakraborty, J. Y. Kravitz, P. W. Thulstrup, L. Hemmingsen, W. F. DeGrado, V. L. Pecoraro, Angew. Chem. 2011, 123, $2097-$ 2101; Angew. Chem. Int. Ed. 2011, 50, 2049-2053.

[16] J. A. Hunt, C. A. Fierke, J. Biol. Chem. 1997, 272, 20364-20372.
[17] H. Song, D. L. Wilson, E. R. Farquhar, E. A. Lewis, J. P. Emerson, Inorg. Chem. 2012, 51, 11098-11105.

[18] M. L. Zastrow, V. L. Pecoraro, J. Am. Chem. Soc. 2013, 135, $5895-5903$.

[19] R. G. Khalifah, J. Biol. Chem. 1971, 246, 2561-2573.

[20] C. A. Fierke, T. L. Calderone, J. F. Krebs, Biochemistry 1991, 30 , $11054-11063$.

[21] P. Woolley, Nature 1975, 258, 677-682.

[22] J. Huguet, R. S. Brown, J. Am. Chem. Soc. 1980, 102, 7571-7572.

[23] R. S. Brown, N. J. Curtis, J. Huguet, J. Am. Chem. Soc. 1981, 103, $6953-6959$.

[24] R. S. Brown, D. Salmon, N. J. Curtis, S. Kusuma, J. Am. Chem. Soc. 1982, 104, 3188-3194.

[25] H. Slebocka-Tilk, J. L. Cocho, Z. Frakman, R. S. Brown, J. Am Chem. Soc. 1984, 106, 2421-2431.

[26] X. Zhang, R. van Eldik, T. Koike, E. Kimura, Inorg. Chem. 1993, $32,5749-5755$.

[27] X. Zhang, R. van Eldik, Inorg. Chem. 1995, 34, 5606-5614.

[28] K. Nakata, N. Shimomura, N. Shiina, M. Izumi, K. Ichikawa, M. Shiro, J. Inorg. Biochem. 2002, 89, 255-266.

[29] J. E. Jackman, K. M. Merz, C. A. Fierke, Biochemistry 1996, 35, $16421-16428$

[30] D. A. Jewell, C. Tu, S. R. Paranawithana, S. M. Tanhauser, P. V. LoGrasso, P. J. Laipis, D. N. Silverman, Biochemistry 1991, 30, $1484-1490$.

[31] A. Looney, R. Han, K. McNeill, G. Parkin, J. Am. Chem. Soc. 1993, 115, 4690-4697.

[32] K. Nakata, M. K. Uddin, K. Ogawa, K. Ichikawa, Chem. Lett. 1997, $991-992$.

[33] S. Yamaguchi, I. Tokairin, Y. Wakita, Y. Funahashi, K. Jitsukawa, H. Masuda, Chem. Lett. 2003, 32, 406-407.

[34] J. F. Krebs, J. A. Ippolito, D. W. Christianson, C. A. Fierke, J. Biol. Chem. 1993, 268, 27458-27466.

[35] L. Koziol, C. A. Valdez, S. E. Baker, E. Y. Lau, W. C. Floyd III, S. E. Wong, J. H. Satcher, Jr., F. C. Lightstone, R. D. Aines, Inorg. Chem. 2012, 51, 6803-6812. 